\title{
BMJ Open Retrospective angiographic study to determine the effect of atherosclerotic stenoses of upstream arteries on the degree of atherosclerosis in distal vascular territories
}

\author{
Rafael Rehwald, ${ }^{1}$ Johannes Petersen, ${ }^{1}$ Alexandra Gratl, ${ }^{2}$ Heinz Zoller, ${ }^{3}$ \\ Andreas Mader, ${ }^{1}$ Alexander Loizides, ${ }^{1}$ Astrid E Grams, ${ }^{4}$ Josef Klocker, ${ }^{3}$ \\ Bernhard Glodny ${ }^{1}$
}

To cite: Rehwald $\mathrm{R}$, Petersen J, Gratl A, et al. Retrospective angiographic study to determine the effect of atherosclerotic stenoses of upstream arteries on the degree of atherosclerosis in distal vascular territories. BMJ Open 2016;6:e010704. doi:10.1136/bmjopen-2015010704

- Prepublication history for this paper is available online. To view these files please visit the journal online (http://dx.doi.org/10.1136/ bmjopen-2015-010704).

Received 27 November 2015 Revised 7 April 2016 Accepted 29 April 2016

CrossMark

For numbered affiliations see end of article.

\section{Correspondence to} Dr Johannes Petersen; johannes.petersen@i-med.ac. at

\section{ABSTRACT}

Objective: Experimental coarctation of the aorta prevents the development of downstream atherosclerosis. The aim of this study was to find out whether or not atherosclerotic stenoses protect distal vascular territories from developing atherosclerosis in humans.

Design and setting: A total of 2125 vascular segments from angiographies of 101 patients were evaluated by calculating the maximum degree of stenosis (NASCET criteria), the degree of calcification, the degree of collaterals and the Friesinger score.

Results: Stenosis $\geq 30-49 \%$ was found in 685 vascular segments $(32.2 \%), \geq 50-69 \%$ in $490(23.1 \%)$, $\geq 70-89 \%$ in $373(17.6 \%)$ and $\geq 90 \%$ in $265(12.5 \%)$. If a stenosis of at least $\geq 70-89 \%$ was present in the common iliac, the external iliac or the common femoral artery, the degrees of stenosis distal to it were lower than those on the contralateral side $(19.8 \pm 22.3 \%$ (Cl 11.7 to 28.0 ) vs $25.2 \pm 20.7 \%$ (Cl 21.2 to 29.1 ); Friesinger scores $1.1 \pm 1.2(\mathrm{Cl} 0.6$ to 1.5$)$ vs $1.4 \pm 1.1(\mathrm{Cl}$ 1.2 to 1.6); degrees of calcification $0.8 \pm 1.0(\mathrm{Cl} 0.4$ to 1.1) vs $1.2 \pm 1.1$ ( $\mathrm{Cl} 1.2$ to 1.6$) ; p<0.05$ each). This effect depended on the degree of proximal stenosis, but not on collaterals, and was most pronounced distal to stenoses of the common iliac, the superficial femoral and the popliteal artery. In regression models, stenoses of the pelvic arteries were shown to be an independent protective factor for the distal vascular territories.

Conclusions: Atherosclerotic stenoses seem to protect distal vascular territories from developing atherosclerosis. The underlying pathophysiological mechanism of this phenomenon remains to be determined. It could be based on pulse pressure reduction.

\section{INTRODUCTION}

There are several patterns of 'arterial occlusive disease' in great arteries ${ }^{1}$ involving either mainly the coronary arteries, the

\section{Strengths and limitations of this study}

Stenoses in arteries can protect distal vascular territories from developing stenoses, wall irregularities and calcifications-the observation that vascular territories distal to a stenosis of the pelvic or femoropopliteal arteries are affected by atherosclerosis to a lesser extent has never been circumstantiated before.

- The degree of stenosis of the common iliac artery and the external iliac artery is a protective factor independent of other protective or risk factors.

- The protective effect of stenoses as low as 30 $49 \%$ was demonstrated.

- The hypothesis that not just the level of blood pressure itself but also the pulse pressure is relevant for developing atherosclerosis cannot be proved by the present data.

- Further research is needed in order to elucidate the probable pathophysiological mechanism, that is, the pulse pressure reduction.

branches of the aortic arch, the visceral branches of the aorta or the distal aorta and its branches. Combinations of these patterns also occur. ${ }^{1}$ The distal aorta and its branches can have iliac, femoropopliteal or infragenual patterns of occlusive disease depending on the various vascular risk factors. ${ }^{2}$ Women are more predisposed to a femoropopliteal, diffuse distribution of the disease, ${ }^{3}$ whereas men tend to have an iliac pattern. ${ }^{2}$ Smoking causes an aortoiliac pattern, ${ }^{2}$ while diabetes ${ }^{2}$ and kidney failure ${ }^{4}$ are more likely to affect peripheral vessels. Arterial hypertension puts all vascular territories equally at risk. ${ }^{2}$

Additionally, local anatomical and physiological conditions are also significant, ${ }^{5}$ namely, the phenomena of "stress concentration" and 
'wall fatigue due to pulsatile blood pressure. ${ }^{5}$ The extent of stress at a given location is a function of the shape of the cross section, the wall thickness and the outer curvature of the artery ${ }^{5}$ as well as the heart rate, blood pressure and blood pressure amplitude. ${ }^{5}$ Therefore, origins of branches of arteries or the inner curvature of a curving artery in patients with a high heart rate are especially at risk. ${ }^{5}$

In animal experiments, the atheroprotective effect of the introduction of stenoses by coarctation of the aorta as a local anatomical protective condition is well established. $^{6-8}$ In humans, it is known that intramyocardial segments of the coronary arteries are usually free of atherosclerosis. This is explained by the lower transmural pressure gradients and thus lower mural stress in comparison with free epicardial segments. ${ }^{9}$ A similar principle is speculated as an explanation ${ }^{5}$ of the rhythmic location of atherosclerotic lesions in the extraosseous-but not in the intraosseous-segments of the vertebral artery. ${ }^{10}$ The observation that vascular territories distal to a clinical relevant stenosis of the pelvic or femoropopliteal arteries are affected by atherosclerosis to a lesser extent is familiar to many physicians involved in the treatment of the patients but has never been circumstantiated.

This study aims to investigate the hypothesis that stenoses of great arteries are capable of protecting distant distal vascular territories from developing atherosclerosis in humans.

\section{METHODS AND MATERIALS}

Approval to conduct this study was obtained from the Ethics Committee of the Medical University of Innsbruck (no. AN2015-0198). The study was conducted in compliance with the most recent revision of the Declaration of Helsinki. The digital subtraction angiographies of the pelvis and legs of 101 consecutive Caucasian patients (31 women and 70 men, mean age $66.1 \pm 10.8$ years (CI 64.0 to 68.2)) were used. Demographic data of the patients, their clinical condition and risk factors are presented in table 1. All 101 patients had atherosclerosis. Ninety-nine patients (98\%) had peripheral arterial occlusive disease of at least Fontaine stage IIb (Rutherford classification $\mathrm{I} / 3),{ }^{11} 12$ one stage II (I/1) patient had a popliteal aneurysm and one stage I $(0 / 0)$ patient had an infrarenal aortic aneurysm. There were no treatment options for 13 patients $(12.9 \%), 7$ patients $(6.9 \%)$ underwent surgical treatment (patch angioplasty of the common femoral artery (CFA) and superficial femoral artery (SFA) or popliteal bypass), 66 patients were treated with a stent $(65.3 \%), 11(10.9 \%)$ patients with a balloon angioplasty and 2 patients (2\%) with a stent in one region and a posterior tibial artery (PTA) in another region. A total of 86 $(85.1 \%)$ patients came to at least one follow-up, 11 patients $(10.9 \%)$ died within the follow-up period of 4 \pm 3.6 months and 7 patients required amputation -1 at the thigh and 6 at the foot.

The examinations were made on a Siemens Artis Zee angiography system (Siemens Healthcare, Erlangen,
Germany) or a Philips Allura Xper FD20 (Philips Healthcare, Best, the Netherlands), using a ruler. The arteries were divided into the following segments: infrarenal aorta, common iliac artery (CIA), external iliac artery (EIA), internal iliac artery (IIA), CFA, deep femoral artery (DFA), SFA, popliteal artery (PI, PII and PIII), tibiofibular trunk (TFT), anterior tibial artery (ATA), PTA and fibular artery (FA). There were a total of 2125 vascular segments (table 2). The following parameters were examined and evaluated by consensus of two radiologists:

1. The maximum degree of stenosis in each segment of a vessel was quantified using the NASCET criteria. ${ }^{13}$ For this purpose, the difference in the diameters in and distal to the stenosis was divided by the distal diameter.

The Friesinger score of the segment, a six-point atherosclerosis score, was developed for coronary angiography. ${ }^{14}$ The score 0 indicates no arteriographic abnormality, $1=$ trivial irregularities with stenoses from $1 \%$ to $29 \%$, 2=localized luminal narrowing of $30-68 \%$, $3=$ multiple luminal narrowing of $30-68 \%$ in the same vessel, $4=$ luminal narrowing of $69-99 \%$ and $5=$ total occlusion.

The degree of calcification on a scale of $0-5$, with 0 meaning no calcification, $1=$ slight, $2=$ low grade, $3=$ moderate, 4=high-grade and $5=$ =xtreme calcification with voluminous deposits that cause protrusion of the vascular wall.

2. The degree of collaterals in each vascular segment began with ' 0 ' in segments with no collaterals. Slight collaterals at the detection limit were classified as ' 1 ', low-grade collaterals as ' 2 ', moderate collaterals as ' 3 ', good collaterals as ' 4 ' and very pronounced collaterals as ' 5 '.

For these evaluations, a Picture Acquisition and Communication System (IMPAX EE R20 VII P1; Agfa HealthCare NV, Mortsel, Belgium) was used. The 3D data set came from a volume-rendering reconstruction of a CT angiography of the pelvis and legs (General Electric Discovery 750 CT; General Electric Company, Fairfield, Connecticut, USA). The reconstruction was made at a 3D postprocessing workstation (Advantage Workstation 4.6/VolumeShare 5; General Electric Company).

In addition, a qualitative evaluation was made of the risk factors such as smoking, arterial hypertension, diabetes and kidney failure and of the use of statins, antihypertensives, antidiabetics, anticoagulants or antiplatelets. Blood pressure and the pulse wave index (PWI) were recorded.

To analyse the data, descriptive statistics were first created using Excel (Office 2007; Microsoft Corp., Seattle, Washington, USA). Distributions were examined using the Shapiro-Wilk test (Graph Pad Prism 6, GraphPad Software Inc, La Jolla, California, USA). Mann-Whitney or Levene test was used to investigate possible differences in the values or variances between 
Table 1 Baseline characteristics of the patient group, as well as of the group divided into women and men

\begin{tabular}{lllllll}
\hline & All & Mean \pm SD & Women & Mean \pm SD & Men & Mean \pm SD \\
\hline $\mathrm{N}$ & $101(100 \%)$ & - & $31(30.7 \%)$ & - & - & $70(69.3 \%)$ \\
Legs & $202(100 \%)$ & - & $62(30.7 \%)$ & - & $140(69.3 \%)$ & - \\
Age & $38-91$ & $66.1 \pm 10.8$ & $46-89$ & $69.7 \pm 10.8$ & $38-91$ & $64.5 \pm 10.5$ \\
BMl & $15.8-41.1$ & $25.8 \pm 4.7$ & $15.8-41.1$ & $24.6 \pm 5.2$ & $16.6-39.9$ & $25.9 \pm 4.4$ \\
BP syst. & $113-190$ & $154.8 \pm 18.9$ & $113-185$ & $153.2 \pm 18.5$ & $117-190$ & $155.5 \pm 19.2$ \\
BP diast. & $50-109$ & $80.7 \pm 11.2$ & $50-105$ & $79.0 \pm 11.5$ & $57-109$ & $81.5 \pm 11.2$
\end{tabular}

DM

Y

N

CKD

$\mathrm{Y}$

Control

Y

N

NA

Major amputation

$\mathrm{Y}$

N

Deceased

$\mathrm{Y}$

N

OAC

$\mathrm{Y}$

N

HMG-CoA RI

$Y$

$\mathrm{N}$

APD

$\mathrm{Y}$

$\mathrm{N}$

Smoker

$Y$

N

Arterial hypertension

Y

$\mathrm{N}$

Fontaine stages

$$
\begin{aligned}
& 1 \\
& 2 \\
& 3 \\
& 4
\end{aligned}
$$

Collaterals

Iliac arteries

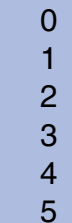

Femoropopliteal arteries

0

1
2
3
4
5

Infragenual arteries

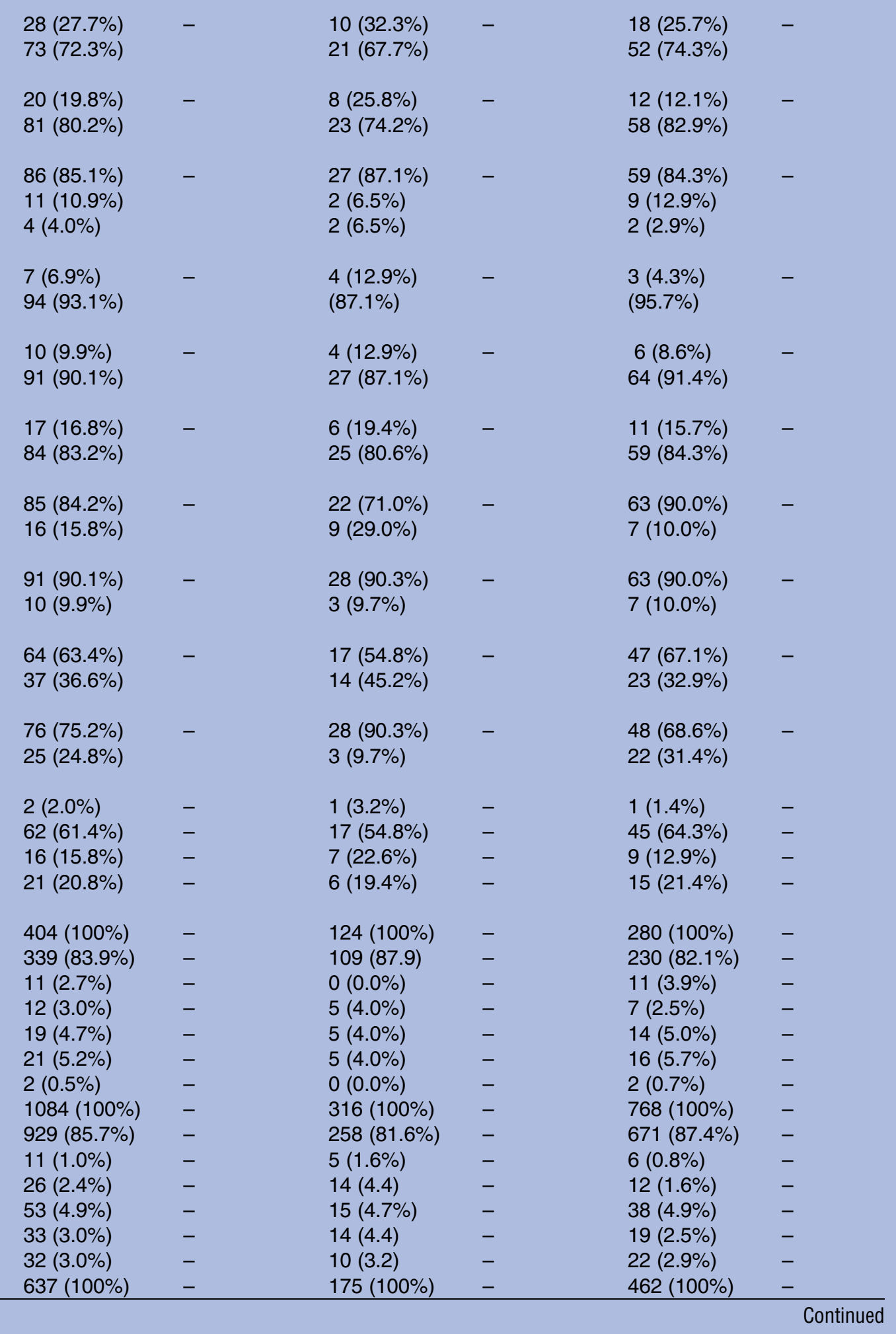


Table 1 Continued

\begin{tabular}{|c|c|c|c|c|c|c|}
\hline & All & Mean $\pm S D$ & Women & Mean $\pm S D$ & Men & Mean $\pm S D$ \\
\hline 0 & $526(82.6 \%)$ & - & $143(81.7 \%)$ & - & 383 (82.9\%) & - \\
\hline 1 & $52(8.2 \%)$ & - & $14(8.0 \%)$ & - & $38(8.2 \%)$ & - \\
\hline 2 & $31(4.9 \%)$ & - & $11(6.3 \%)$ & - & $20(4.3 \%)$ & - \\
\hline 3 & $20(3.1 \%)$ & - & $5(2.9 \%)$ & - & $15(3.2 \%)$ & - \\
\hline 4 & $8(1.3 \%)$ & - & $2(1.1 \%)$ & - & $6(1.3 \%)$ & - \\
\hline 5 & $0(0.0 \%)$ & - & $0(0.0 \%)$ & - & $0(0.0 \%)$ & - \\
\hline
\end{tabular}

APD, antiplatelet drug; BMI, body mass index; BP, blood pressure; CKD, chronic kidney disease; DM, diabetes mellitus; N, no.; OAC, oral anticoagulation; RI, (HMG-CoA-) reductase inhibitor; Y, yes.

the right and the left side; Spearman's correlation test was used to measure the agreement of the data between the right and left sides. A $r<0.19$ was considered to be an indicator of a very weak correlation, 0.2-0.39 weak, $0.4-0.59$ moderate, $0.6-0.79$ strong and $>0.8$ was a very strong correlation. After this analysis, the data on sides were discarded, that is, they were now classified as side affected by a stenosis and contralateral side. Then, the stenoses of the pelvic arteries were arbitrarily classified in groups of $0-29 \%, 30-49 \%, 50-69 \%, 70-89 \%$ and $90-$ $100 \%$ stenosis. Depending on the degree of stenosis at each level, for example, of the CIA, two groups of patients were formed, namely, those with a stenosis of that degree and those without. The segments of the lower limb distal to the respective 'classification level' were assigned to one of the two groups accordingly and compared with one another with respect to the NASCET degree of stenosis, the Friesinger score and the severity of calcification using the Mann-Whitney test. Frequency analyses of the variables 'degree of stenosis (NASCET) ', 'the Friesinger score' and 'severity of calcification' yielded two groups of histograms: a group with a relatively low percentage of more severe lesions (CIA, EIA, CFA) and a group with a higher percentage of more severe lesions (SFA, PI, PII, PIII). In order to present the effect of stenosis of the pelvic vascular territory as an example of the results, a binning was conducted on the basis of the frequency analyses so that the CFA was grouped with the CIA and EIA. The most severe stenosis in the CIA/EIA/CFA was assessed as a classification criterion. The data distal to the lesion were normalised to those on the contralateral side so that they could be expressed in \% of the contralateral side $(0 \%)$. They were entered on an ordinate over the corresponding segment location on the abscissa. The classification of the data according to the degree of stenosis of the main stem of the IIA, on which no distal territories of the thigh depend, was used as an internal control. Finally, linear regression analyses were conducted on the factor 'degree of stenosis (NASCET)' at every level, first including all factors, and then based on these models in forward stepwise selection procedures (SPSS V.23; IBM Corp., Armonk, New York, USA). Other significant risk factors for peripheral arterial occlusive disease were also considered. Adjustment was made for diabetes mellitus, smoking, age, arterial hypertension and the use of statins. To present the results, the software Prism V.6 (Graph Pad Prism; GraphPad Software), Adobe Illustrator CC (Adobe Systems Inc, San José, California, USA) and CorelDraw Graphics Suite X7 (Corel Corp, Ottawa, Ontario, Canada) were used. A p $<0.05$ was considered to be significant.

\section{RESULTS}

The main risk factors for peripheral arterial occlusive disease (PAOD) in the group were arterial hypertension $(\mathrm{n}=76 ; 75.2 \%)$, smoking $(\mathrm{n}=64 ; 63.4 \%)$, diabetes $(\mathrm{n}=28$; $27.7 \%)$ and kidney failure $(\mathrm{n}=20 ; 19.8 \%)$. Two patients (2\%) had Fontaine stage I PAOD, $62(61.4 \%)$ had stage IIb, $16(15.8 \%)$ had stage III and $21(20.8 \%)$ had stage IV. The initial procedure was successful in all 86 patients; 13 patients required a reintervention and/or a second procedure during the follow-up period to improve flow to or from the same limb (table 1). In eight cases, this was a femoral bifurcation reconstruction and/or femoropopliteal bypass, in four cases an additional endovascular procedure and in one case lysis. Of a total of 2125 segments of vessels, 685 $(32.2 \%)$ had stenosis of $\geq 30-49 \%, 490(23.1 \%) \geq 50-69 \%$, $373(17.6 \%) \geq 70-89 \%$ and $265(12.5 \%) \geq 90 \%$ (table 2 ).

The diameters of all segments of vessels were distributed normally; all other parameters were not distributed normally. The medians, means and variances of all parameters were the same on both sides. The severity of the stenoses, Friesinger scores and calcification correlated horizontally, weakly to moderately $(\mathrm{p}<0.0001$ each $)$ and longitudinally, very weakly to moderately $(\mathrm{p}<0.0001)$.

If at least one stenosis $\geq 30-49 \%$ was present along the pelvic axis (CIA, EIA, CFA), the degrees of stenosis distal to it were lower than those on the contralateral side $(23.3 \pm 21.3 \%$ (CI 18.9 to 27.7 ) vs $25.3 \pm 20.9 \%$ (CI 19.2 to 31.5 ); Friesinger scores: $1.3 \pm 1.1$ (CI 1.0 to 1.5 ) vs $1.5 \pm 1.2$ (CI 1.1 to 1.8); degrees of calcification: $1.0 \pm 1.1$ (CI 0.8 to 1.2 ) vs $1.2 \pm 1.2$ (CI 0.9 to 1.6 ), $p>0.05$ each). If at least one stenosis $\geq 50-69 \%$ was present, the degrees of stenosis distal to it were lower than those on the contralateral side $(21.0 \pm 19.0 \%$ (CI 16.1 to 26.0$)$ vs 26.2 $\pm 22.3 \%$ (CI 21.1 to 31.2 ), $\mathrm{p}>0.05$; Friesinger scores: 1.1 \pm 1.0 (CI 0.8 to 1.4 ) vs $1.5 \pm 1.2$ (CI 1.3 to 1.8 ), $\mathrm{p}=0.007$; degrees of calcification: $0.8 \pm 1$ (CI 0.6 to 1.1 ) vs $1.3 \pm 1.2$ (CI 1.0 to 1.5 ), $\mathrm{p}=0.0225$ ). If at least one stenosis $\geq 70$ $89 \%$ was present, the degrees of stenosis distal to it were 
Table 2 Absolute and relative numbers of stenoses within the arbitrarily stated ranges of degree in the respective arterial segments; numbers of Friesinger scores and degrees of calcification

\begin{tabular}{|c|c|c|c|c|c|c|c|c|c|c|c|c|c|c|c|c|c|}
\hline \multirow[b]{2}{*}{ Vessel } & \multirow[b]{2}{*}{$\mathbf{N}$} & \multicolumn{4}{|c|}{ Degree of stenosis (NASCET) } & \multicolumn{6}{|c|}{ Friesinger score (0-5) } & \multicolumn{6}{|c|}{ Degree of calcification (0-5) } \\
\hline & & $30-50 \%$ & $50-70 \%$ & $70-90 \%$ & $\geq 90 \%$ & 0 & 1 & 2 & 3 & 4 & 5 & $\overline{0}$ & 1 & 2 & 3 & 4 & 5 \\
\hline \multirow[t]{2}{*}{$\mathrm{CIA}$} & 202 & 86 & 47 & 27 & 14 & 26 & 87 & 52 & 7 & 17 & 13 & 37 & 40 & 44 & 43 & 24 & 14 \\
\hline & & $42.6 \%$ & $23.3 \%$ & $13.4 \%$ & $6.9 \%$ & $12.9 \%$ & $43.1 \%$ & $25.7 \%$ & $3.5 \%$ & $8.4 \%$ & $6.4 \%$ & $18.3 \%$ & $19.8 \%$ & $21.8 \%$ & $21.3 \%$ & $11.9 \%$ & $6.9 \%$ \\
\hline \multirow[t]{2}{*}{ EIA } & 202 & 72 & 49 & 24 & 9 & 26 & 87 & 52 & 7 & 17 & 13 & 78 & 50 & 26 & 25 & 19 & 4 \\
\hline & & $35.6 \%$ & $24.3 \%$ & $11.9 \%$ & $4.5 \%$ & $12.9 \%$ & $43.1 \%$ & $25.7 \%$ & $3.5 \%$ & $8.4 \%$ & $6.4 \%$ & $38.6 \%$ & $24.8 \%$ & $12.9 \%$ & $12.4 \%$ & $9.4 \%$ & $2.0 \%$ \\
\hline \multirow[t]{2}{*}{ IIA } & 202 & 82 & 60 & 43 & 27 & 49 & 75 & 34 & 1 & 18 & 25 & 81 & 49 & 35 & 17 & 15 & 5 \\
\hline & & $40.6 \%$ & $29.7 \%$ & $21.3 \%$ & $13.4 \%$ & $24.3 \%$ & $37.1 \%$ & $16.8 \%$ & $0.5 \%$ & $8.9 \%$ & $12.4 \%$ & $40.1 \%$ & $24.3 \%$ & $17.3 \%$ & $8.4 \%$ & $7.4 \%$ & $2.5 \%$ \\
\hline \multirow[t]{2}{*}{ CFA } & 201 & 36 & 17 & 8 & 2 & 64 & 102 & 26 & 1 & 6 & 2 & 81 & 57 & 35 & 19 & 6 & 3 \\
\hline & & $17.9 \%$ & $8.5 \%$ & $4.0 \%$ & $1.0 \%$ & $31.8 \%$ & $50.7 \%$ & $12.9 \%$ & $0.5 \%$ & $3.0 \%$ & $1.0 \%$ & $40.3 \%$ & $28.4 \%$ & $17.4 \%$ & $9.5 \%$ & $3.0 \%$ & $1.5 \%$ \\
\hline \multirow[t]{2}{*}{ DFA } & 195 & 20 & 9 & 3 & 2 & 107 & 70 & 14 & 1 & 1 & 2 & 120 & 42 & 22 & 7 & 2 & 2 \\
\hline & & $10.3 \%$ & $4.6 \%$ & $1.5 \%$ & $1.0 \%$ & $54.9 \%$ & $35.9 \%$ & $7.2 \%$ & $0.5 \%$ & $0.5 \%$ & $1.0 \%$ & $61.5 \%$ & $21.5 \%$ & $11.3 \%$ & $3.6 \%$ & $1.0 \%$ & $1.0 \%$ \\
\hline \multirow[t]{2}{*}{ SFA } & 192 & 108 & 87 & 73 & 44 & 50 & 33 & 19 & 19 & 23 & 48 & 60 & 21 & 21 & 33 & 22 & 35 \\
\hline & & $56.3 \%$ & $45.3 \%$ & $38.0 \%$ & $22.9 \%$ & $26.0 \%$ & $17.2 \%$ & $9.9 \%$ & $9.9 \%$ & $12.0 \%$ & $25.0 \%$ & $31.3 \%$ & $10.9 \%$ & $10.9 \%$ & $17.2 \%$ & $11.5 \%$ & $18.2 \%$ \\
\hline \multirow[t]{2}{*}{$\mathrm{PI}$} & 166 & 48 & 30 & 25 & 22 & 61 & 56 & 24 & 1 & 3 & 21 & 73 & 38 & 18 & 46 & 8 & 13 \\
\hline & & $28.9 \%$ & $18.1 \%$ & $15.1 \%$ & $13.3 \%$ & $36.7 \%$ & $33.7 \%$ & $14.5 \%$ & $0.6 \%$ & $1.8 \%$ & $12.7 \%$ & $44.0 \%$ & $22.9 \%$ & $10.8 \%$ & $9.6 \%$ & $4.8 \%$ & $7.8 \%$ \\
\hline \multirow[t]{2}{*}{ PII } & 168 & 34 & 25 & 22 & 21 & 75 & 57 & 11 & 2 & 1 & 22 & 87 & 37 & 19 & 10 & 4 & 11 \\
\hline & & $20.2 \%$ & $14.9 \%$ & $13.1 \%$ & $12.5 \%$ & $44.6 \%$ & $33.9 \%$ & $6.5 \%$ & $1.2 \%$ & $0.6 \%$ & $13.1 \%$ & $43.1 \%$ & $18.3 \%$ & $9.4 \%$ & $5.0 \%$ & $2.0 \%$ & $5.4 \%$ \\
\hline \multirow[t]{2}{*}{ PIII } & 162 & 29 & 21 & 18 & 17 & 104 & 30 & 7 & 0 & 2 & 19 & 109 & 28 & 8 & 6 & 2 & 9 \\
\hline & & $17.9 \%$ & $13.0 \%$ & $11.1 \%$ & $10.5 \%$ & $64.2 \%$ & $18.5 \%$ & $4.3 \%$ & $0.0 \%$ & $1.2 \%$ & $11.7 \%$ & $67.3 \%$ & $17.3 \%$ & $4.9 \%$ & $3.7 \%$ & $1.2 \%$ & $5.6 \%$ \\
\hline \multirow[t]{2}{*}{ TFT } & 150 & 26 & 19 & 15 & 15 & 92 & 31 & 8 & 2 & 1 & 16 & 105 & 18 & 9 & 5 & 3 & 10 \\
\hline & & $17.3 \%$ & $12.7 \%$ & $10.0 \%$ & $10.0 \%$ & $61.3 \%$ & $20.7 \%$ & $5.3 \%$ & $1.3 \%$ & $0.7 \%$ & $10.7 \%$ & $70.0 \%$ & $12.0 \%$ & $6.0 \%$ & $3.3 \%$ & $2.0 \%$ & $6.7 \%$ \\
\hline \multirow[t]{2}{*}{ ATA } & 166 & 58 & 48 & 44 & 33 & 86 & 24 & 8 & 3 & 6 & 39 & 114 & 16 & 5 & 9 & 9 & 13 \\
\hline & & $34.9 \%$ & $28.9 \%$ & $26.5 \%$ & $19.9 \%$ & $51.8 \%$ & $14.5 \%$ & $4.8 \%$ & $1.8 \%$ & $3.6 \%$ & $23.5 \%$ & $68.7 \%$ & $9.6 \%$ & $3.0 \%$ & $5.4 \%$ & $5.4 \%$ & $7.8 \%$ \\
\hline \multirow[t]{2}{*}{ PTA } & 157 & 53 & 50 & 47 & 36 & 79 & 27 & 3 & 1 & 3 & 44 & 102 & 22 & 10 & 4 & 5 & 14 \\
\hline & & $33.8 \%$ & $31.8 \%$ & $29.9 \%$ & $22.9 \%$ & $50.3 \%$ & $17.2 \%$ & $1.9 \%$ & $0.6 \%$ & $1.9 \%$ & $28.0 \%$ & $65.0 \%$ & $14.0 \%$ & $6.4 \%$ & $2.5 \%$ & $3.2 \%$ & $8.9 \%$ \\
\hline \multirow[t]{2}{*}{$\mathrm{FA}$} & 164 & 33 & 28 & 24 & 23 & 85 & 40 & 8 & 0 & 0 & 31 & 113 & 22 & 16 & 3 & 2 & 8 \\
\hline & & $20.1 \%$ & $17.1 \%$ & $14.6 \%$ & $14.0 \%$ & $51.8 \%$ & $24.4 \%$ & $4.9 \%$ & $0.0 \%$ & $0.0 \%$ & $18.9 \%$ & $68.9 \%$ & $13.4 \%$ & $9.8 \%$ & $1.8 \%$ & $1.2 \%$ & $4.9 \%$ \\
\hline
\end{tabular}

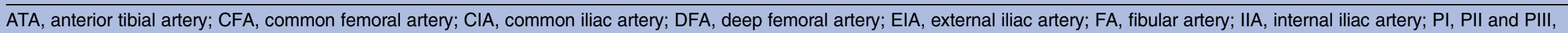
popliteal artery segment I, II or III; PTA, posterior tibial artery; SFA, superficial femoral artery; TFT, tibiofibular trunk. 
lower than those on the contralateral side $(19.8 \pm 22.3 \%$ (CI 11.7 to 28.0 ) vs $25.2 \pm 20.7 \%$ (CI 21.2 to 29.1), $\mathrm{p}=0.028$; Friesinger scores: $1.1 \pm 1.2$ (CI 0.6 to 1.5 ) vs 1.4 \pm 1.1 (CI 1.2 to 1.6$), p=0.0245$; degrees of calcification: $0.8 \pm 1.0$ (CI 0.4 to 1.1 ) vs $1.2 \pm 1.1$ (CI 1.2 to 1.6 ), $\mathrm{p}=0.0195$ ). If at least one stenosis $\geq 90 \%$ was present, the degrees of stenosis distal to it were lower than those on the contralateral side $(23.3 \pm 24.7 \%$ (CI 8.4 to 38.3$)$ vs 24 $\pm 20.8 \%$ (CI 20.4 to 27.7 ); Friesinger scores: $1.2 \pm 1.3$ (CI 0.4 to 2.0 ) vs $1.4 \pm 1.1$ (CI 1.1 to 1.6 ); degrees of calcification: $0.7 \pm 0.7$ (CI 0.3 to 1.1 ) vs $1.1 \pm 1.1, \mathrm{p}>0.05$ each).

The main stem of the IIA was used as an internal control. If a stenosis of at least $\geq 30-49 \%$ was present in this location, the degrees of stenosis distal to it were the same as on the contralateral side $(24.5 \pm 20.5 \%$ (CI 19.1 to 29.9 ) vs $23.6 \pm 21.6 \%$ (CI 18.8 to 28.4 ); Friesinger scores: $1.4 \pm 1.1$ (CI 1.1 to 1.7 ) vs $1.3 \pm 1.2$ (CI 1.1 to 1.6 ); degrees of calcification: $1.1 \pm 1.1$ (CI 0.8 to 1.4 ) vs $1.1 \pm 1.1$ (CI 0.8 to 1.3 ), $>>0.05$ each). If a stenosis of at least $\geq 50-69 \%$ was present, the degrees of stenosis distal to it were the same as on the contralateral side $(25.2 \pm 21.6 \%$ (CI 18.7 to 31.7 ) vs $23.4 \pm 20.9 \%$ (CI 19.1 to 27.7); Friesinger scores: $1.4 \pm 1.2$ (CI 1.1 to 1.8 ) vs $1.3 \pm 1.2$ (CI 1.1 to 1.5 ); degrees of calcification: $1.1 \pm 1.1$ (CI 0.8 to 1.5 ) vs $1.0 \pm 1.1$ (CI 0.8 to 1.3 ), $p>0.05$ each). If a stenosis of at least $\geq 70-89 \%$ was present, the degrees of stenosis distal to it were the same as on the contralateral side (24.4 $\pm 23 \%$ (CI 16.4 to 32.4 ) vs $23.8 \pm 20.7 \%$ (CI 19.8 to 27.8); Friesinger scores: $1.3 \pm 1.2$ (CI 0.9 to 1.7 ) vs $1.4 \pm 1.2$ (CI 1.1 to 1.6); degrees of calcification: $1 \pm 1.2$ (CI 0.6 to 1.5 ) vs $1 \pm 1.2$ (CI 0.9 to 1.3 ), $\mathrm{p}>0.05$ each). If a stenosis of at least $\geq 90 \%$ was present, the degrees of stenosis distal to it were the same as on the contralateral side (25.6 $\pm 24.6 \%$ (CI 14.7 to 36.5 ) vs $23.7 \pm 20.5 \%$ (CI 20.0 to 127.4); Friesinger scores: $1.4 \pm 1.3$ (CI 0.8 to 1.9 ) vs 1.3 \pm 1.1 (CI 1.1 to 1.5 ); degrees of calcification: $1.1 \pm 1.3$ (CI 0.6 to 1.7 ) vs $1.1 \pm 1.1$ (CI 0.8 to 1.2 ), $\mathrm{p}>0.05$ each).

The significance levels of all tests of the differences between the segments in relation to the respective classification level are shown in table 3. The effects were most pronounced for stenoses of the CIA and the SFA.

The mean value of the iliac collaterals was estimated to be $0.5 \pm 0.9$ (CI 0.3 to 0.6 ), femoropopliteal collaterals $0.5 \pm 0.7$ (CI 0.4 to 0.6 ) and infragenual collaterals 0.3 \pm 0.5 (CI 0.2 to 0.4 ) (table 1 ). The degree of stenosis of the arteries based on the NASCET correlated poorly, with a Spearman $\mathrm{r}=0.3$, but highly significantly ( $p=0.002)$ with the degree of collaterals. The degree of stenosis of the CIA and EIA did not correlate with the collaterals of the CIA and EIA $(\mathrm{r}=0.079 ; \mathrm{p}=0.264)$, but correlated very weakly negatively with the femoropopliteal and crural arteries, respectively $(\mathrm{r}=-0.158, \mathrm{p}=0.046$; $\mathrm{r}=-0.166, \mathrm{p}=0.046)$. The degree of stenosis in the femoropopliteal arteries did not correlate with the collaterals of the CIA and EIA ( $\mathrm{r}=-0.075, \mathrm{p}=0.347)$ but correlated moderately with those of the femoropopliteal and crural arteries $(\mathrm{r}=0.565, \mathrm{p}<0.0001 ; \mathrm{r}=0.412, \mathrm{p}<0.0001)$. The degree of stenosis in the crural arteries did not correlate with the collaterals of the CIA and EIA ( $r=-0.161$, $\mathrm{p}=0.052$ ) but correlated weakly to moderately with those of femoropopliteal and crural arteries, respectively $(\mathrm{r}=0.36, \mathrm{p}<0.0001 ; \mathrm{r}=0.525, \mathrm{p}<0.0001)$.

Figure 1 shows the association of stenoses of pelvic vessels (CIA/EIA/CFA) $\geq 30-49 \%$; $\geq 50-69 \%, \geq 70-89 \%$ or $\geq 90 \%$ with the extent of the degrees of stenosis distal to them as a percentage comparison with the contralateral side, calcifications and the Friesinger scores.

Figure 2 shows the standardised coefficients (standardised for the risk factors diabetes mellitus, smoking, age, hypertension, etc) of the independent risk factors identified on the regression models with respect to the degree of maximum stenosis at the pelvic level and in the femoropopliteal and crural regions. In the pelvic level, smoking was found to be the most important risk factor before the IIA collaterals, the diastolic blood pressure and the PWI; in the femoropopliteal region, it was PWI before SFA collaterals, HMG-CoA reductase inhibitors, popliteal artery first segment collaterals and oral anticoagulation. The degree of stenosis in the pelvis (NASCET) was found to be an independent protective factor. In the crural region, the degree of FA collaterals was the most significant influencing factor before the TFT collaterals, patient age, PTA collaterals and PWI.

\section{DISCUSSION}

This study shows that stenoses in arteries can protect distal vascular territories from developing stenoses, wall irregularities and calcification. This applies to stenosis as mild as $30 \%$ (NASCET). If the stenosis is located in the CIA, associated reductions in the degree of stenosis are found in the EIA, not in the CFA, but even more pronounced in the femoropopliteal and infragenual arteries. Stenoses in the EIA or CFA are less significant, but stenoses in the femoropopliteal region have an atheroprotective effect on almost every vascular territory distal to these segments. When the pelvic-leg vascular territory is subdivided into the pelvic level, the femoropopliteal level and the infragenual level, ${ }^{2}$ the degree of stenosis at the iliac level is a protective factor, before the development of femoropopliteal stenoses, independent of the other important risk factors.

As expected, smoking ${ }^{2}$ was the most important risk factor for the degree of iliac stenoses, before IIA collaterals, diastolic blood pressure and PWI. The most important risk factor for femoropopliteal stenoses was PWI, before SFA collaterals, statins as a surrogate parameter for hypercholesterolemia, the PA first segment collaterals and oral anticoagulation. The only protective factor was the degree of iliac stenosis: a high NASCET degree of iliac stenosis protects the femoropopliteal vascular region. The risk factors for the infragenual arteries included the familial disposition, TFT, PTA collaterals, age and PWI.

Stenoses of the main stem of the IIA used as an internal control were not correlated with lesser degrees 
Table 3 Significance levels of all tests of the differences between the segments in relation to the respective classification level

\begin{tabular}{|c|c|c|c|c|c|c|c|c|c|c|c|c|c|c|c|c|c|c|c|c|c|c|c|c|c|c|c|c|c|c|c|c|c|c|c|c|c|}
\hline \multirow[t]{2}{*}{ Difference } & \multirow[t]{2}{*}{ NASCET } & \multicolumn{3}{|c|}{ EIA } & \multicolumn{3}{|c|}{ IIA } & \multicolumn{3}{|c|}{ CFA } & \multicolumn{3}{|c|}{ DFA } & \multicolumn{3}{|c|}{ SFA } & \multicolumn{3}{|l|}{ PI } & \multicolumn{3}{|l|}{ PII } & PIII & & & TF & & & AT & & & PT & & & FA & & \\
\hline & & $\overline{\mathbf{N}}$ & $\mathbf{F}$ & C & $\overline{\mathbf{N}}$ & $\mathbf{F}$ & $\mathbf{C}$ & $\overline{\mathbf{N}}$ & $\mathbf{F}$ & $\mathbf{C}$ & $\overline{\mathbf{N}}$ & $\mathbf{F}$ & $\mathbf{C}$ & $\overline{\mathbf{N}}$ & $\mathbf{F}$ & $\mathbf{C}$ & $\overline{\mathbf{N}}$ & $\mathbf{F}$ & C & $\overline{\mathbf{N}}$ & $\mathbf{F}$ & $\mathbf{C}$ & $\overline{\mathbf{N}}$ & $\mathbf{F}$ & C & $\overline{\mathbf{N}}$ & $\mathbf{F}$ & $\mathbf{C}$ & $\overline{\mathbf{N}}$ & $\mathbf{F}$ & $\mathbf{C}$ & $\overline{\mathbf{N}}$ & $\mathbf{F}$ & $\mathbf{C}$ & $\overline{\mathbf{N}}$ & $F$ & C \\
\hline$\overline{\mathrm{CIA}}$ & $30-49 \%$ & $\mathrm{n}$ & $y$ & $\mathrm{n}$ & $\mathrm{n}$ & $\mathrm{n}$ & $\mathrm{n}$ & $\mathrm{n}$ & $\mathrm{n}$ & $\mathrm{n}$ & $\mathrm{n}$ & $n$ & $\mathrm{n}$ & $y$ & $\mathrm{y}$ & $y$ & $y$ & $y$ & $n$ & $y$ & $\mathrm{y}$ & $y$ & $y$ & $y$ & $n$ & $y$ & $\mathrm{y}$ & $y$ & $\mathrm{n}$ & $n$ & $n$ & $y$ & $\mathrm{n}$ & $\mathrm{n}$ & $\mathrm{n}$ & $\mathrm{n}$ & $\mathrm{n}$ \\
\hline & $50-69 \%$ & $y$ & $n$ & $\mathrm{n}$ & $\mathrm{n}$ & $\mathrm{n}$ & $\mathrm{n}$ & $\mathrm{n}$ & $\mathrm{n}$ & $\mathrm{n}$ & $y$ & $y$ & $\mathrm{y}$ & $\mathrm{y}$ & $y$ & $y$ & $y$ & $y$ & $\mathrm{n}$ & $\mathrm{y}$ & $y$ & $y$ & $y$ & $y$ & $y$ & $y$ & $y$ & $y$ & $\mathrm{n}$ & $\mathrm{n}$ & $\mathrm{n}$ & $n$ & $\mathrm{n}$ & $y$ & $n$ & $\mathrm{n}$ & $\mathrm{n}$ \\
\hline & $70-89 \%$ & $y$ & $\mathrm{n}$ & $\mathrm{n}$ & $\mathrm{n}$ & $n$ & $\mathrm{n}$ & $n$ & $n$ & $\mathrm{n}$ & $y$ & $y$ & $y$ & $y$ & $y$ & $y$ & $y$ & $y$ & $n$ & $y$ & $y$ & $n$ & $y$ & $y$ & $y$ & $n$ & $y$ & $y$ & $\mathrm{n}$ & $\mathrm{n}$ & $y$ & $y$ & $\mathrm{n}$ & $y$ & $n$ & $\mathrm{n}$ & $y$ \\
\hline & $\geq 90$ & $y$ & $\mathrm{n}$ & $\mathrm{n}$ & $\mathrm{n}$ & $\mathrm{n}$ & $\mathrm{n}$ & $n$ & $\mathrm{n}$ & $\mathrm{n}$ & $y$ & $n$ & $n$ & $n$ & $y$ & $y$ & $n$ & $n$ & $\mathrm{n}$ & $y$ & $n$ & $\mathrm{n}$ & $y$ & $n$ & $n$ & $\mathrm{n}$ & $n$ & $n$ & $\mathrm{n}$ & $\mathrm{n}$ & $n$ & $n$ & $n$ & $y$ & $n$ & $\mathrm{n}$ & $y$ \\
\hline EIA & $30-49 \%$ & & & & $\mathrm{n}$ & $\mathrm{n}$ & $\mathrm{n}$ & $y$ & $y$ & $y$ & $n$ & $n$ & $\mathrm{n}$ & $n$ & $n$ & $n$ & $\mathrm{n}$ & $\mathrm{n}$ & $n$ & $\mathrm{n}$ & $\mathrm{n}$ & $\mathrm{n}$ & $n$ & $n$ & $n$ & $\mathrm{n}$ & $\mathrm{n}$ & $n$ & $\mathrm{n}$ & $\mathrm{n}$ & $n$ & $n$ & $n$ & $n$ & $n$ & $\mathrm{n}$ & $n$ \\
\hline & $50-69 \%$ & & & & $\mathrm{n}$ & $\mathrm{n}$ & $\mathrm{n}$ & $y$ & $n$ & $n$ & $\mathrm{n}$ & $n$ & $n$ & $n$ & $\mathrm{n}$ & $\mathrm{n}$ & $\mathrm{n}$ & $\mathrm{n}$ & $y$ & $\mathrm{n}$ & $y$ & $\mathrm{n}$ & $\mathrm{n}$ & $\mathrm{n}$ & $y$ & $\mathrm{n}$ & $\mathrm{n}$ & $n$ & $\mathrm{n}$ & $\mathrm{n}$ & $y$ & $\mathrm{n}$ & $\mathrm{n}$ & $n$ & $\mathrm{n}$ & $\mathrm{n}$ & $\mathrm{n}$ \\
\hline & $70-\varepsilon$ & & & & $\mathrm{n}$ & $n$ & $\mathrm{n}$ & $\mathrm{n}$ & $n$ & $\mathrm{n}$ & $n$ & $n$ & $\mathrm{n}$ & $\mathrm{n}$ & $n$ & $n$ & $n$ & $\mathrm{n}$ & $\mathrm{n}$ & $\mathrm{n}$ & $n$ & $\mathrm{n}$ & $n$ & $n$ & $\mathrm{n}$ & $n$ & $n$ & $n$ & $n$ & $n$ & $n$ & $n$ & $\mathrm{n}$ & $n$ & $y$ & $y$ & $\mathrm{n}$ \\
\hline & $\geq 90$ & & & & $\mathrm{n}$ & $\mathrm{n}$ & $n$ & $n$ & $\mathrm{n}$ & $\mathrm{n}$ & $\mathrm{n}$ & $n$ & $\mathrm{n}$ & $\mathrm{n}$ & $\mathrm{n}$ & $\mathrm{n}$ & $\mathrm{n}$ & $\mathrm{n}$ & $n$ & $n$ & $\mathrm{n}$ & $\mathrm{n}$ & $\mathrm{n}$ & $\mathrm{n}$ & $n$ & $\mathrm{n}$ & $\mathrm{n}$ & $n$ & $\mathrm{n}$ & $\mathrm{n}$ & $\mathrm{n}$ & $\mathrm{n}$ & $n$ & $n$ & $n$ & $n$ & $\mathrm{n}$ \\
\hline IIA & $30-49 \%$ & & & & & & & $\mathrm{n}$ & $n$ & $\mathrm{n}$ & $n$ & $n$ & $\mathrm{n}$ & $\mathrm{n}$ & $\mathrm{n}$ & $n$ & $\mathrm{n}$ & $\mathrm{n}$ & $\mathrm{n}$ & $\mathrm{n}$ & $\mathrm{n}$ & $n$ & $n$ & $\mathrm{n}$ & $\mathrm{n}$ & $\mathrm{n}$ & $\mathrm{n}$ & $n$ & $\mathrm{n}$ & $\mathrm{n}$ & $n$ & $n$ & $n$ & $n$ & $n$ & $\mathrm{n}$ & $\mathrm{n}$ \\
\hline & $50-$ & & & & & & & $\mathrm{n}$ & $\mathrm{n}$ & $\mathrm{n}$ & $\mathrm{n}$ & $\mathrm{n}$ & $\mathrm{n}$ & $\mathrm{n}$ & $\mathrm{n}$ & $\mathrm{n}$ & $\mathrm{n}$ & $\mathrm{n}$ & $\mathrm{n}$ & $\mathrm{n}$ & $\mathrm{n}$ & $\mathrm{n}$ & $\mathrm{n}$ & $\mathrm{n}$ & $\mathrm{n}$ & $\mathrm{n}$ & $\mathrm{n}$ & $\mathrm{n}$ & $\mathrm{n}$ & $\mathrm{n}$ & $\mathrm{n}$ & $\mathrm{n}$ & $n$ & $n$ & $n$ & $\mathrm{n}$ & $\mathrm{n}$ \\
\hline & $70-8$ & & & & & & & $\mathrm{n}$ & $n$ & $\mathrm{n}$ & $n$ & $n$ & $\mathrm{n}$ & $\mathrm{n}$ & $\mathrm{n}$ & $\mathrm{n}$ & $\mathrm{n}$ & $\mathrm{n}$ & $\mathrm{n}$ & $\mathrm{n}$ & $\mathrm{n}$ & $\mathrm{n}$ & $\mathrm{n}$ & $\mathrm{n}$ & $\mathrm{n}$ & $\mathrm{n}$ & $\mathrm{n}$ & $\mathrm{n}$ & $\mathrm{n}$ & $\mathrm{n}$ & $\mathrm{n}$ & $\mathrm{n}$ & $\mathrm{n}$ & $\mathrm{n}$ & $\mathrm{n}$ & $\mathrm{n}$ & $\mathrm{n}$ \\
\hline & $\geq 90$ & & & & & & & $n$ & $n$ & $n$ & $n$ & $n$ & $n$ & $n$ & $n$ & $n$ & $n$ & $n$ & $n$ & $n$ & $n$ & $\mathrm{n}$ & $n$ & $n$ & $n$ & $n$ & $n$ & $n$ & $n$ & $n$ & $n$ & $n$ & $n$ & $n$ & $n$ & $n$ & $\mathrm{n}$ \\
\hline CFA & $30-49 \%$ & & & & & & & & & & $n$ & $n$ & $\mathrm{n}$ & $\mathrm{y}$ & $y$ & $y$ & $n$ & $\mathrm{n}$ & $\mathrm{n}$ & $n$ & $\mathrm{y}$ & $n$ & $n$ & $y$ & $n$ & $\mathrm{n}$ & $n$ & $n$ & $y$ & $n$ & $n$ & $n$ & $n$ & $n$ & $n$ & $n$ & $\mathrm{n}$ \\
\hline & 50 & & & & & & & & & & $n$ & $n$ & $\mathrm{n}$ & $y$ & $y$ & $n$ & $n$ & $\mathrm{n}$ & $n$ & $\mathrm{n}$ & $n$ & $\mathrm{n}$ & $\mathrm{n}$ & $n$ & $n$ & $n$ & $\mathrm{n}$ & $n$ & $n$ & $\mathrm{n}$ & $n$ & $\mathrm{n}$ & $n$ & $n$ & $n$ & $\mathrm{n}$ & $\mathrm{n}$ \\
\hline & $70-89 \%$ & & & & & & & & & & $n$ & $n$ & $\mathrm{n}$ & $\mathrm{n}$ & $n$ & $\mathrm{n}$ & $\mathrm{n}$ & $\mathrm{n}$ & $\mathrm{n}$ & $\mathrm{n}$ & $\mathrm{n}$ & $\mathrm{n}$ & $n$ & $n$ & $\mathrm{n}$ & $\mathrm{n}$ & $n$ & $\mathrm{n}$ & $\mathrm{n}$ & $\mathrm{n}$ & $\mathrm{n}$ & $\mathrm{n}$ & $\mathrm{n}$ & $n$ & $n$ & $\mathrm{n}$ & $\mathrm{n}$ \\
\hline & $\geq 90$ & & & & & & & & & & $n$ & $n$ & $\mathrm{n}$ & $\mathrm{n}$ & $\mathrm{n}$ & $n$ & $n$ & $\mathrm{n}$ & $n$ & $\mathrm{n}$ & $\mathrm{n}$ & $n$ & $n$ & $\mathrm{n}$ & $\mathrm{n}$ & $\mathrm{n}$ & $\mathrm{n}$ & $n$ & $n$ & $n$ & $n$ & $n$ & $\mathrm{n}$ & $\mathrm{n}$ & $n$ & $n$ & $\mathrm{n}$ \\
\hline DFA & $30-49 \%$ & & & & & & & & & & & & & $\mathrm{y}$ & $y$ & $n$ & $y$ & $\mathrm{y}$ & $y$ & $y$ & $y$ & $y$ & $y$ & $y$ & $y$ & $y$ & $y$ & $y$ & $y$ & $y$ & $y$ & $\because$ & $\mathrm{y}$ & $n$ & $n$ & $\mathrm{y}$ & $\mathrm{n}$ \\
\hline & $50-$ & & & & & & & & & & & & & $y$ & $y$ & $\mathrm{n}$ & $y$ & $y$ & $n$ & $y$ & $y$ & $n$ & $n$ & $y$ & $n$ & $y$ & $y$ & $\mathrm{n}$ & $y$ & $y$ & $y$ & $n$ & $\mathrm{n}$ & $n$ & $n$ & $y$ & $\mathrm{n}$ \\
\hline & $70-8$ & & & & & & & & & & & & & $n$ & $\mathrm{n}$ & $y$ & $n$ & $n$ & $n$ & $y$ & $y$ & $\mathrm{n}$ & $\mathrm{n}$ & $y$ & $n$ & $y$ & $y$ & $n$ & $y$ & $y$ & $y$ & $\pi$ & $n$ & $n$ & n & $y$ & $\mathrm{n}$ \\
\hline & $\geq 90$ & & & & & & & & & & & & & $n$ & $\mathrm{n}$ & $\mathrm{n}$ & $\mathrm{n}$ & $\mathrm{n}$ & $\mathrm{n}$ & $\mathrm{n}$ & $n$ & $\mathrm{n}$ & $y$ & $n$ & $n$ & $y$ & $\mathrm{n}$ & $\mathrm{n}$ & $n$ & $\mathrm{n}$ & $y$ & $\mathrm{n}$ & $n$ & $n$ & y & $y$ & $y$ \\
\hline SFA & $30-49 \%$ & & & & & & & & & & & & & & & & $y$ & $y$ & $y$ & $y$ & $\mathrm{y}$ & $y$ & $y$ & $y$ & $y$ & $y$ & $\mathrm{y}$ & $y$ & $y$ & $y$ & $y$ &. & $\mathrm{y}$ & $y$ & n & $\mathrm{y}$ & $y$ \\
\hline & 5 & & & & & & & & & & & & & & & & $y$ & $y$ & $y$ & $y$ & $y$ & $y$ & $y$ & $y$ & $y$ & $y$ & $y$ & $y$ & $y$ & $y$ & $\mathrm{n}$ & $y$ & $y$ & $\mathrm{y}$ & $n$ & $\mathrm{y}$ & $y$ \\
\hline & 70 & & & & & & & & & & & & & & & & $\mathrm{y}$ & $y$ & $y$ & $\mathrm{y}$ & $\mathrm{y}$ & $y$ & $y$ & $y$ & $\mathrm{n}$ & $\mathrm{n}$ & $\mathrm{y}$ & $y$ & $y$ & $y$ & $\mathrm{n}$ & $y$ & $\mathrm{n}$ & $\mathrm{n}$ & $n$ & $\mathrm{n}$ & $\mathrm{n}$ \\
\hline & $\geq 90$ & & & & & & & & & & & & & & & & $y$ & $y$ & $y$ & $\mathrm{y}$ & $\mathrm{y}$ & $y$ & $y$ & $y$ & $n$ & $y$ & $\mathrm{y}$ & $\mathrm{n}$ & $y$ & $y$ & $\mathrm{n}$ & $y$ & $n$ & $n$ & n & $\mathrm{n}$ & $\mathrm{n}$ \\
\hline $\mathrm{PI}$ & $30-49 \%$ & & & & & & & & & & & & & & & & & & & $y$ & $y$ & $y$ & $y$ & $y$ & $y$ & $y$ & $y$ & $y$ & $y$ & $y$ & $y$ & $j$ & $\mathrm{y}$ & $y$ &  & $y$ & $y$ \\
\hline & 5 & & & & & & & & & & & & & & & & & & & $y$ & $y$ & $y$ & $y$ & $y$ & $y$ & y & $y$ & $y$ & $y$ & $y$ & $\mathrm{n}$ & y & $y$ & $y$ & $y$ & $y$ & $y$ \\
\hline & 7 & & & & & & & & & & & & & & & & & & & $y$ & $y$ & $y$ & $y$ & $y$ & $y$ & $y$ & $\mathrm{y}$ & $\mathrm{n}$ & y & $y$ & $\mathrm{n}$ & $y$ & $y$ & $y$ & $\mathrm{n}$ & $n$ & $\mathrm{n}$ \\
\hline & $\geq 9$ & & & & & & & & & & & & & & & & & & & $y$ & $y$ & $y$ & $y$ & $y$ & $y$ & $y$ & $y$ & $y$ & $y$ & $y$ & $n$ & $y$ & $y$ & $y$ & $y$ & $\mathrm{n}$ & $\mathrm{n}$ \\
\hline PII & $30-49 \%$ & & & & & & & & & & & & & & & & & & & & & & $y$ & $y$ & $y$ & $y$ & $y$ & $y$ & $y$ & $y$ & $y$ & $y$ & $y$ & $y$ & $y$ & $y$ & $y$ \\
\hline & 5 & & & & & & & & & & & & & & & & & & & & & & $y$ & $y$ & $y$ & $y$ & $y$ & $y$ & $y$ & $y$ & $y$ & $y$ & $y$ & $y$ & $y$ & $y$ & $y$ \\
\hline & 7 & & & & & & & & & & & & & & & & & & & & & & $y$ & $y$ & $y$ & $y$ & $y$ & $y$ & $y$ & $y$ & $y$ & $y$ & $y$ & $y$ & $y$ & $y$ & $n$ \\
\hline & $\geq 90$ & & & & & & & & & & & & & & & & & & & & & & $y$ & $y$ & $y$ & $y$ & $y$ & $y$ & $y$ & $y$ & $y$ & $y$ & $y$ & $y$ & $y$ & $y$ & $\mathrm{n}$ \\
\hline ㅁIII & $30-4$ & & & & & & & & & & & & & & & & & & & & & & & & & $y$ & $y$ & $y$ & $y$ & $y$ & $y$ & $y$ & $y$ & $y$ & $n$ & $y$ & $y$ \\
\hline & & & & & & & & & & & & & & & & & & & & & & & & & & $y$ & $\mathrm{y}$ & $y$ & $y$ & $y$ & $n$ & $y$ & $y$ & $y$ & $n$ & $y$ & $n$ \\
\hline & 7 & & & & & & & & & & & & & & & & & & & & & & & & & $y$ & $y$ & $y$ & $y$ & $y$ & $n$ & $y$ & $y$ & $y$ & $y$ & $y$ & $\mathrm{n}$ \\
\hline & $\geq 90$ & & & & & & & & & & & & & & & & & & & & & & & & & $y$ & $y$ & $y$ & $y$ & $y$ & $y$ & $y$ & $y$ & $y$ & $\mathrm{y}$ & $y$ & $\mathrm{n}$ \\
\hline IFT & $30-49 \%$ & & & & & & & & & & & & & & & & & & & & & & & & & & & & $y$ & $y$ & $y$ & $y$ & $y$ & $y$ & $\mathrm{y}$ & $\mathrm{y}$ & $y$ \\
\hline & & & & & & & & & & & & & & & & & & & & & & & & & & & & & $y$ & $y$ & $y$ & $y$ & $y$ & $y$ & $y$ & $y$ & $y$ \\
\hline & 70 & & & & & & & & & & & & & & & & & & & & & & & & & & & & $y$ & $y$ & $y$ & $y$ & $y$ & $y$ & $y$ & $y$ & $y$ \\
\hline & $\geq 90$ & & & & & & & & & & & & & & & & & & & & & & & & & & & & $y$ & $y$ & $y$ & $y$ & $y$ & $y$ & $y$ & $y$ & $y$ \\
\hline
\end{tabular}

The effects are most pronounced for stenoses of the common iliac artery and the superficial femoral artery. No effects of stenoses of the internal iliac arteries, representing a segment without further distant distal depending territories as a virtual internal control.

ATA, anterior tibial artery; C, calcification; CFA, common femoral artery; CIA, common iliac artery; DFA, deep femoral artery; EIA, external iliac artery; F, Friesinger score; FA, fibular artery; IIA,

internal iliac artery; N, NASCET; PI, PII and PIII, popliteal artery segment I. II or III; PTA, posterior tibial artery; SFA, superficial femoral artery; TFT, tibiofibular trunk; y, yes, significant. 
Figure 1 Association of stenoses of pelvic vessels (CIA/ EIA/CFA) 30-49\%; 50-69\%, 70$89 \%$ or $90-100 \%$ with the extent of the degrees of stenosis distal to them as a percentage comparison with $(A)$ the contralateral side, $(B)$ calcifications and $(C)$ the Friesinger scores. Lower degrees of atherosclerotic burdens distal to stenoses of arteries of the pelvic level are striking. CFA, common femoral artery; $\mathrm{ClA}$, common iliac artery; EIA, external iliac artery.

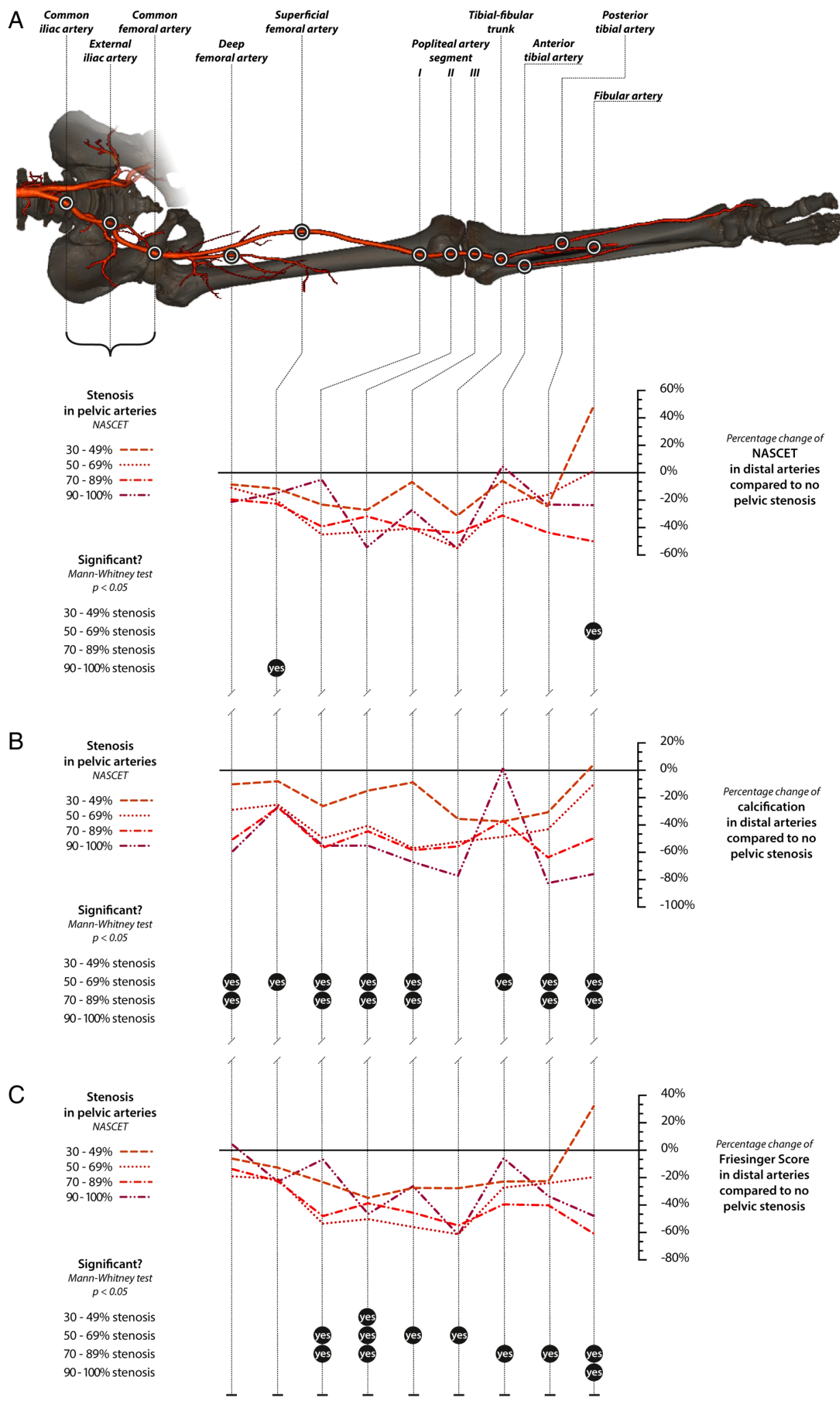

of atherosclerosis in the distal vascular territories: the slight positive correlations of the degrees of stenosis of the IIA with the degrees of stenosis of all other vascular segments were not statistically significant.

This thus supports the hypothesis that not just the level of blood pressure itself, but also the pulse pressure may be relevant for developing atherosclerosis. ${ }^{5}$ While flow acceleration and turbulence occur within stenoses, the flow decelerates in the separation zone immediately downstream. At this location, a recirculation flow causes poststenotic dilatation owing to elevated transmural pressure while $1-2 \mathrm{~cm}$ further distal, laminar flow is restored..$^{15}$ Distal to this, flow is characterised by small, late arterial pulses, known as 'pulsus parvus et tardus', 


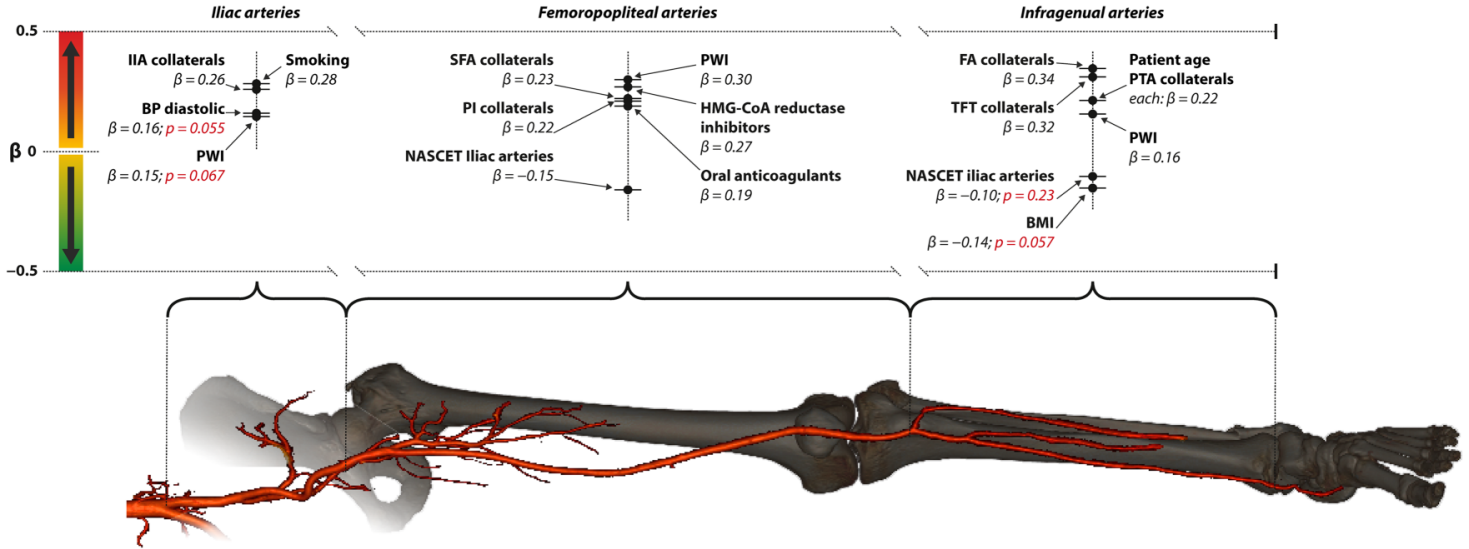

Figure 2 Standardized coefficients of the independent risk factors identified on the regression models with respect to the degree of maximum stenosis at the pelvic level, the femoropopliteal region and the crural region. The degree of stenosis in the pelvis was found to be an independent protective factor of the femoropopliteal region with respect to atherosclerosis. BMI, body mass index; BP, blood pressure; FA, fibular artery; PI, popliteal artery segment I; PTA, posterior tibial artery; PWI, pulse wave index; SFA, superficial femoral artery; TFT, tibiofibular trunk.

which is found in the entire dependent vascular territory. $^{16}$

In comparison with the EIA, the protective effect of the CIA is considerably stronger. This could be attributed to the fact that stenoses of the CIA cannot be collateralised as well as stenoses of the EIA because there is no possibility of diverting via the ipsilateral IIA. The lack of significance of the effect of stenoses of the CFA is likely due to the shortness of this vascular segment and the resulting low number of stenoses, while the pronounced and significant associations of stenoses of the SFA, the popliteal artery and the TFT with less pronounced stenoses, Friesinger scores and degrees of calcification distal to them can be explained by the poor collateralisation options in comparison with the pelvic level. Although no territory distal to the DFA is immediately dependent on it, stenoses at this level appear to be relevant. The reason for this is that most of these cases involved lesions of the bifurcation of the CFA, a pattern that is not rare. ${ }^{17}$ This region meets the conditions for high local stress, such as those that are present at the carotid bifurcation or at the aortic bifurcation: a greater cross section, bending effects, reduced thickness and opposite curvatures. ${ }^{5}$ The femoral bifurcation is therefore considered to be a vulnerable site where an isolated stenosis of the DFA rarely occurs.

The degree of collaterals-iliac and also femoropopliteal and infragenual-seems to be a risk factor for the severity of stenoses (NASCET) (figure 2). This can be interpreted to indicate that existing collaterals reverse the protective effect of the stenoses. This is consistent with the hypothesis that a stenosis can protect from atherosclerosis by reducing pulse pressure and slowing the flow of blood: this effect could also be attenuated again depending on how pronounced the collaterals are. However, this hypothesis is highly speculative and must be verified in future studies. However, it can be assumed with certainty that the formation of collaterals does not in itself have a protective effect on distal vascular territories. It cannot be tested based on available data how long a stenosis has already been present or how much time has thus passed in which collaterals could have formed. The role of collaterals as a risk factor for stenosis in the model (figure 2) can probably be explained only by the fact that the collaterals are an epiphenomenon of long-existing stenoses but are not a 'risk factor'. The weak negative correlation between femoropopliteal and infragenual collaterals and the degree of stenosis in the CIA or EIA are noteworthy. It could be attributable to the fact that the inflow of blood from proximal is less in these cases and that collaterals around another, more distal femoropopliteal or infragenual stenosis therefore remain narrower or do not arise at all. One explanation for the lack of a correlation between iliac stenoses (CIA and EIA) and collaterals is that the collaterals in this vascular territory are highly variable. They can stem from regions that were not contrasted in the same angiography, such as contralateral IIA and the IMA.

This study has limitations. The first limitation that should be mentioned is the retrospective study design, which can be the source of a selection bias. However, the study meets the criteria for evidence level I. ${ }^{18}$ The sample consisted of consecutive patients with pronounced atherosclerosis, the main risk factors for atherosclerosis were represented and the number of 2125 segments evaluated was high. However, the number of patients, although not small at 101, limited the possibilities of multivariate analyses. Additional studies must be conducted to determine the exact extent of the magnitude of the protective effect of stenoses on distal vascular territories. However, the very good agreement of the location-related effects of the standard risk factors with the literature indicates that a good estimate of the magnitude was made. The significance of pulse pressure as a cardiovascular risk factor is well established. ${ }^{19-23}$ It contributes to the development of atherosclerosis 
independently of the classical risk factors. ${ }^{24}$ Although the positive effects of lowering the heart rate ${ }^{525}$ and the blood pressure ${ }^{2627}$ are known, it is still unclear whether or not lowering the pulse pressure results in a protective effect in humans. However, as the study was performed retrospectively, we were not able to measure the pulse pressure distal to the stenoses. This main weakness of the study can only be addressed with prospective, longitudinal observational studies.

If the pulse pressure is confirmed in prospective, longitudinal observational studies to be a risk factor, there would be no immediate clinical consequences. Since the overwhelming majority of patients $(75.2 \%)$ have arterial hypertension as a risk factor for atherosclerosis, these patients at least should be given strict pharmacological antihypertensive treatment. The pulse pressure is thus far not accessible as an independent treatment target. Every antihypertensive treatment also affects the pulse pressure and vice versa. Any existing antihypertensive treatment should never be negatively affected, so if the pulse pressure hypothesis is confirmed, the next step should be to answer the question of whether there are antihypertensive drugs or combinations of standard antihypertensive agents that have a greater effect on the pulse pressure than others and whether a better preventive effect could be achieved with them than with others.

At the moment, the results of this study cannot and should not lead to any changes in patient treatment. If a haemodynamically significant stenosis or occlusion is present, the lesion should be treated by angioplasty, stent angioplasty or bypass-providing there is a clinical necessity-in accordance with the guidelines. ${ }^{28-30}$ Treatment should not be delayed for clinically symptomatic patients, even with less pronounced stenoses, but should be determined on a case-by-case basis and not postponed until critical limb ischaemia develops. It would also not be acceptable to leave a slight residual stenosis untreated in the belief that this could protect the periphery. Every lesion should be treated as well as possible without causing restenosis because residual stenoses can be the cause of restenosis or even thrombosis in a stented segment.

However, dilatations of not clinically manifest, lowgrade stenoses that may possibly never become clinically relevant, which are detected as incidental findings 'in passing' in coronary angiographies, for example, may possibly be counterproductive for the distal vascular territory. In the kidney, for example, this could mean faster progression of glomerulosclerosis and in the supra-aortic region faster progression of cerebral microangiopathy. These hypotheses are another argument for strict compliance with the treatment guidelines, and their proof is pending.

By analogy with the studies of animal experiments, in which the atheroprotective effect of coarctation was proved ${ }^{6-8}$ it is conceivable to attempt experimental modification of the pulse pressure, for example with simple slight bending, but also with flow-modulated stents, which could be similar to those used for reducing a transjugular intrahepatic portosystemic shunt (TIPS). ${ }^{31} 32$ Bending should naturally not be so narrow that it would lead to symptoms, but not so wide that no flow modulation occurs. If a feasible middle ground were found, it would have to be tested in long-term studies.

Longitudinal, prospective studies will be needed to prove the hypothetical negative effect on the distal vascular territory of treating a stenosis. It is probable that the most suitable patients for this will be those with constellations in which a PAOD IIb is present on one side and a non-clinically manifest stenosis is present at the same level on the other side or in which a stenosis of the carotid artery is treated but not an additional contralateral stenosis.

In conclusion, this study shows that atherosclerotic stenoses seem to protect distant distal vascular territories from developing atherosclerosis. The underlying pathophysiological mechanism for this phenomenon remains to be determined but could be the reduction of pulse pressure.

\section{Author affiliations}

${ }^{1}$ Department of Radiology, University Hospital for Radiology, Medical University of Innsbruck, Innsbruck, Tyrol, Austria

${ }^{2}$ Department of Surgery, University Hospital for Vascular Surgery, Medical University of Innsbruck, Innsbruck, Tyrol, Austria

${ }^{3}$ Department of Internal Medicine, University Hospital for Internal Medicine II, Gastroenterology and Hepatology, Medical University of Innsbruck, Innsbruck, Tyrol, Austria

${ }^{4}$ Department of Radiology, University Hospital for Neuroradiology, Medical University of Innsbruck, Innsbruck, Tyrol, Austria

Contributors RR and $B G$ were the main investigators of this study. RR, JP, $A M$ and $B G$ contributed to the conception and design of the work; the acquisition, analysis and interpretation of data for the work; in drafting the work and revising it critically for important intellectual content and in giving final approval of the version to be published. AG, HZ, AL, AEG and JK contributed to the acquisition of data for the work; in partially drafting the work, in revising it critically for important intellectual content and in giving final approval of the version to be published. All authors (RR, JP, AG, HZ, $A M, A L, A E G, J K$ and $B G$ ) agreed to be accountable for all aspects of the work in ensuring that questions related to the accuracy or integrity of any part of the work are appropriately investigated and resolved.

Funding This research received no specific grant from any funding agency in the public, commercial or not-for-profit sectors.

Competing interests None declared.

Ethics approval Ethical committee at the Medical University of Innsbruck.

Provenance and peer review Not commissioned; externally peer reviewed.

Data sharing statement The original data set is available on individual request by emailing the corresponding author, johannes.petersen@i-med.ac.at.

Open Access This is an Open Access article distributed in accordance with the Creative Commons Attribution Non Commercial (CC BY-NC 4.0) license, which permits others to distribute, remix, adapt, build upon this work noncommercially, and license their derivative works on different terms, provided the original work is properly cited and the use is non-commercial. See: http:// creativecommons.org/licenses/by-nc/4.0/

\section{REFERENCES}

1. DeBakey ME, Lawrie GM, Glaeser DH. Patterns of atherosclerosis and their surgical significance. Ann Surg 1985;201:115-31. 
2. Diehm N, Shang A, Silvestro A, et al. Association of cardiovascular risk factors with pattern of lower limb atherosclerosis in 2659 patients undergoing angioplasty. Eur J Vasc Endovasc Surg 2006;31:59-63.

3. Ortmann J, Nuesch E, Traupe T, et al. Gender is an independent risk factor for distribution pattern and lesion morphology in chronic critical limb ischemia. J Vasc Surg 2012;55:98-104.

4. Wasmuth S, Baumgartner I, Do DD, et al. Renal insufficiency is independently associated with a distal distribution pattern of symptomatic lower-limb atherosclerosis. Eur J Vasc Endovasc Surg 2010;39:591-6.

5. Thubrikar MJ, Robicsek F. Pressure-induced arterial wall stress and atherosclerosis. Ann Thorac Surg 1995;59:1594-603.

6. Lyon RT, Runyon-Hass A, Davis HR, et al. Protection from atherosclerotic lesion formation by reduction of artery wall motion. J Vasc Surg 1987;5:59-67.

7. Magarey FR, Roser BJ, Stehbens WE, et al. Effects of experimental coarctation of the aorta on atheroma in sheep. J Pathol Bacteriol 1965;90:129-33.

8. Snyder DD, Campbell GS. Effect of aortic constriction on experimental atherosclerosis in rabbits. Proc Soc Exp Biol Med 1958;99:563-4.

9. Robicsek F, Thubrikar MJ. The freedom from atherosclerosis of intramyocardial coronary arteries: reduction of mural stress-a key factor. Eur J Cardiothorac Surg 1994;8:228-35.

10. Meyer WW. On the rhythmic localization of atherosclerotic Foci in the cervical segment of the vertebral artery. Beitr Pathol Anat 1964;130:24-39.

11. Fontaine R, Kim M, Kieny R. Die chirurgische Behandlung der peripheren Durchblutungsstörungen. Helv Chir Acta 1954;5/6: 199-233.

12. Rutherford RB, Baker JD, Ernst C, et al. Recommended standards for reports dealing with lower extremity ischemia: revised version. $J$ Vasc Surg 1997;26:517-38.

13. European Carotid Surgery Trialists' Collaborative Group. Randomised trial of endarterectomy for recently symptomatic carotid stenosis: final results of the MRC European Carotid Surgery Trial (ECST). Lancet 1998;351:1379-87.

14. Friesinger GC, Page EE, Ross RS. Prognostic significance of coronary arteriography. Trans Assoc Am Physicians 1970;83: 78-92.

15. Meola M, Petrucci I. Color Doppler sonography in the study of chronic ischemic nephropathy. J Ultrasound 2008;11:55-73.

16. Kotval PS. Doppler waveform parvus and tardus. A sign of proximal flow obstruction. J Ultrasound Med 1989;8:435-40.
17. Dufranc J, Palcau L, Heyndrickx M, et al. Technique and results of femoral bifurcation endarterectomy by eversion. J Vasc Surg 2015;61:728-33.

18. Sauaia A, Moore EE, Crebs JL, et al. Evidence level of individual studies: a proposed framework for surgical research. J Trauma Acute Care Surg 2012;72:1484-90.

19. Klassen PS, Lowrie EG, Reddan DN, et al. Association between pulse pressure and mortality in patients undergoing maintenance hemodialysis. JAMA 2002;287:1548-55.

20. Glynn RJ, Chae CU, Guralnik JM, et al. Pulse pressure and mortality in older people. Arch Intern Med 2000;160:2765-72.

21. Benetos A, Rudnichi A, Safar M, et al. Pulse pressure and cardiovascular mortality in normotensive and hypertensive subjects. Hypertension 1998;32:560-4.

22. Domanski MJ, Davis BR, Pfeffer MA, et al. Isolated systolic hypertension: prognostic information provided by pulse pressure. Hypertension 1999;34:375-80.

23. Franklin SS, Khan SA, Wong ND, et al. Is pulse pressure useful in predicting risk for coronary heart disease? The Framingham Heart Study. Circulation 1999;100:354-60.

24. Winston GJ, Palmas W, Lima J, et al. Pulse pressure and subclinica cardiovascular disease in the multi-ethnic study of atherosclerosis. Am J Hypertens 2013;26:636-42.

25. A randomized trial of propranolol in patients with acute myocardial infarction. I. Mortality results. JAMA 1982;247:1707-14.

26. Effects of treatment on morbidity in hypertension. Results in patients with diastolic blood pressures averaging 115 through $129 \mathrm{~mm} \mathrm{Hg}$. JAMA 1967;202:1028-34.

27. Effects of treatment on morbidity in hypertension. II. Results in patients with diastolic blood pressure averaging 90 through $114 \mathrm{~mm}$ Hg. JAMA 1970;213:1143-52.

28. Rossi M, lezzi R. Cardiovascular and Interventional Radiological Society of Europe guidelines on endovascular treatment in aortoiliac arterial disease. Cardiovasc Intervent Radiol 2014;37:13-25.

29. Norgren L, Hiatt WR, Dormandy JA, et al. Inter-society consensus for the management of peripheral arterial disease (TASC II). J Vasc Surg 2007;45(Suppl S):S5-67.

30. Norgren L, Hiatt WR, Dormandy JA, et al. Inter-society consensus for the management of peripheral arterial disease (TASC II). Eur J Vasc Endovasc Surg 2007;33(Suppl 1):S1-75.

31. Saket RR, Sze DY, Razavi MK, et al. TIPS reduction with use of stents or stent-grafts. J Vasc Interv Radiol 2004;15:745-51.

32. Farsad K, Kolbeck KJ, Keller FS, et al. Primary creation of an externally constrained TIPS: a technique to control reduction of the portosystemic gradient. AJR Am J Roentgenol 2015;204:868-71. 